\title{
Advanced Orofacial Rhabdomyosarcoma: A Retrospective Study of 31 Cases
}

\author{
Naima Otmani ${ }^{1}$ Mohamed Khattab ${ }^{1}$ \\ 1 Pediatric Hematology and Oncology Unit, Children's Hospital of \\ Rabat, Rabat, Morocco
}

Int Arch Otorhinolaryngol 2016;20:207-211.

\begin{abstract}
Address for correspondence Naima Otmani, MD, PhD, Pediatric Hematology and Oncology Unit, Children's Hospital of Rabat, Rabat Instituts, Rabat 10000, Morocco (e-mail: onaima2000@yahoo.fr).
\end{abstract}

\begin{abstract}
Keywords

- rhabdomyosarcoma

- orofacial

- children
\end{abstract}

\section{Introduction}

Rhabdomyosarcoma (RMS) is the most common histologic type of soft tissue sarcoma in children, accounting for $6 \%$ of all malignancies in patients under 15 years of age. ${ }^{1,2}$ Males have a slight predilection, with a male-to-female ratio of $1.3-1 .^{3}$ The most common sites of this tumor in children are head and neck (35\%), followed by the genitourinary tract (23\%), and extremities (17\%). ${ }^{4}$ Head and neck locations are anatomically divided into two categories: parameningeal (including RMS of the nose, nasopharynx, paranasal sinuses, middle ear, mastoid, infratemporal fossa, and pterygopalatine fossa) and non-parameningeal (including RMS of the scalp, orbit, parotid gland, oral cavity, oropharynx, and larynx). Oral lesions are uncommon and account for $10-12 \%$ of all head and neck RMS cases. ${ }^{4,5}$

Based on the morphologic features and molecular analysis, the current World Health Organization classification categorizes RMS into three main subtypes: embryonal (encompassing the botryoid, spindle cell, and anaplastic variants), alveolar (including the solid variant), and pleomorphic. ${ }^{6}$ There are certain distinctive clusters of features regarding age at diagnosis, site of primary location, and histology. Embryonal subtypes are often localized with a favorable prognosis; in contrast, alveolar subtypes present with distant metastasis and less favorable prognosis. received

June 16, 2015

accepted

September 28, 2015

published online

February 19, 2016
DOI http://dx.doi.org/

10.1055/s-0035-1570117. ISSN $1809-9777$.
Copyright $\odot 2016$ by Thieme Publicações License terms Ltda, Rio de Janeiro, Brazil 
Despite improved outcomes of children with RMS in developed countries, survival rates of patients in limitedresource countries continue to remain poor. ${ }^{7}$ Poverty, illiteracy, advanced stage at presentation, lack of access to health care, and poor treatment infrastructure pose a major challenge in management of cancer in these countries. This paper aims to explore the epidemiological and pathological characteristics among children with orofacial RMS visiting one of the most important pediatric oncology centers of Morocco. The results can help in developing management strategies to improve the outcomes of our patients.

\section{Material and Methods}

We performed this retrospective study at a pediatric hematology and oncology unit from January 2003 to December 2013. Our unit is one of the five Moroccan units dedicated to pediatric oncology, where $\sim 350$ newly-diagnosed children with cancer receive treatment annually. Despite improvements in recent years, prevention and treatment of childhood cancer continue to face challenges such as absence of standards for the diagnosis and treatment management, inadequate health coverage with high cost of management, lack of information and communication with patients, and unavailability of palliative care and psychosocial support. Hence, more epidemiological studies in these fields are needed in our country for good monitoring and better planning of health services.

For this study, children affected by histologically confirmed RMS occurring as a primary lesion in the oral and orofacial area were included. Exclusion criteria included incomplete clinical data, orbital tumors, reports with doubtful or controversial diagnosis, and cases of non-Moroccan nationals. We retrospectively reviewed medical records, pathology reports, imaging, surgical treatment, chemotherapy, and radiotherapy protocols. Patients were assigned according to the surgical-histopathologic grouping system used in the inter-group rhabdomyosarcoma studies $^{8}$ ( - Table 1 ), and to the clinical TNM pretreatment staging system based on site, size, clinical regional nodal status, and distant spread, using preoperative imaging and physical findings ${ }^{9}$ (- Table 2).

Treatment included chemotherapy, surgery, and radiation therapy. Chemotherapy was used for primary cytoreduction and eradication of gross and micrometastases; local therapy (radiotherapy and/or surgery) was performed in residual

Table 1 Surgical-histopathologic grouping system used in the inter-group rhabdomyosarcoma studies ${ }^{8}$

\begin{tabular}{|l|}
\hline Group I: \\
\hline Localized disease, completely resected \\
\hline A- Confined to organ or muscle of origin \\
\hline B- Infiltration outside organ or muscle of origin \\
\hline Group II: \\
\hline Compromised or regional resection, including: \\
\hline A- Grossly resected tumors with microscopic residual tumor \\
\hline B- Regional disease, completely resected, with nodes involved, and/or tumor extension into an adjacent organ \\
\hline C- Regional disease with involved nodes, grossly resected, but with evidence of microscopic residual tumor \\
\hline Group III: \\
\hline Incomplete resection or biopsy with gross residual disease remaining \\
\hline Group IV: \\
\hline Distant metastases present at onset \\
\hline
\end{tabular}

Table 2 Soft Tissue Sarcoma Committee of the Children's Oncology Group: Pretreatment Staging System ${ }^{9}$

\begin{tabular}{|c|c|c|c|c|c|}
\hline Stage & Sites of Primary Tumor & T Stage & $\begin{array}{l}\text { Tumor } \\
\text { Size }\end{array}$ & $\begin{array}{l}\text { Regional } \\
\text { Lymph Nodes }\end{array}$ & $\begin{array}{l}\text { Distant } \\
\text { Metastasis }\end{array}$ \\
\hline 1 & $\begin{array}{l}\text { orbit, head and neck (non- parameningeal), } \\
\text { genitourinary organ (not bladder or prostate), biliary tract }\end{array}$ & $\mathrm{T} 1$ or $\mathrm{T} 2$ & any size & N0 or N1 or NX & M0 \\
\hline 2 & $\begin{array}{l}\text { bladder, prostate, arm or leg, parameningeal region, other } \\
\text { (thorax, abdomen, peritoneum) }\end{array}$ & $\mathrm{T} 1$ or $\mathrm{T} 2$ & $\mathrm{a}, \leq 5 \mathrm{~cm}$ & N0 or NX & M0 \\
\hline \multirow[t]{2}{*}{3} & \multirow{2}{*}{$\begin{array}{l}\text { bladder, prostate, arm or leg, parameningeal region, other } \\
\text { (thorax, abdomen, retroperitoneum) }\end{array}$} & \multirow[t]{2}{*}{$\mathrm{T} 1$ or $\mathrm{T} 2$} & $\mathrm{a}, \leq 5 \mathrm{~cm}$ & N1 & \multirow[t]{2}{*}{ M0 } \\
\hline & & & $\mathrm{b},>5 \mathrm{~cm}$ & N0 or N1 or NX & \\
\hline 4 & any site & $\mathrm{T} 1$ or $\mathrm{T} 2$ & any size & $\mathrm{N} 0$ or $\mathrm{N} 1$ or $\mathrm{NX}$ & M1 \\
\hline
\end{tabular}

Abbreviations: M0, absence of metastatic spread; M1, presence of metastatic spread beyond the primary site and regional lymph nodes; N0, absence of nodal spread; N1, presence of regional nodal spread beyond the primary site; T1, tumor confined to anatomic site of origin (noninvasive); $\mathrm{T} 2 \mathrm{a}$, tumor extension and/or fixation to surrounding tissue (invasive), tumor $\leq 5 \mathrm{~cm}$ in maximum diameter; $\mathrm{T} 2 \mathrm{~b}$, tumor extension and/or fixation to surrounding tissue (invasive), tumor $>5 \mathrm{~cm}$ in maximum diameter; $\mathrm{X}$, unknown $\mathrm{N}$ status. 
tumor cases. Chemotherapy regimens were as follow: vincristine, actinomycin D, cyclophosphamide (VAC); ifosfamide, vincristine, actinomycin D (IVA); vincristine, actinomycin D, doxorubicin (VAD); carboplatin, epirubicin, and vincristine (CEV); vincristine, ifosfamide, etoposide (VIE).

Summary statistics were used to describe the studied population. The estimated survival probabilities were calculated using the Kaplan-Meier method. We valuated event-free survival (EFS) from the date of diagnosis to the date of disease progression, recurrence, or death due to any cause.

\section{Results}

Out of 181 patients diagnosed with RMS in our institution between 2004 and 2013, 31 (17.2\%) had orofacial location. The median age of patients was $8 \pm 4.22$ years (range: 3 months - 15 years). There were 20 boys (64.5\%) and 11 girls (35.5\%); with a male to female ratio of 1.8:1 ( - Table 3 ).

When residence location was classified using rural-urban areas, $41.9 \%$ of the patients lived in rural areas. The mean distance between the patients' residence and our center of treatment. More than $70 \%$ of the patients did not have health care insurance and less than $55 \%$ had a low socioeconomic status.

Clinical manifestations of the malignancy varied largely depending on the areas involved in the tumor. The main drivers for patients to seek treatment were accelerated

Table 3 Distribution of patients by selected sociodemographic characteristics $(n=31)$

\begin{tabular}{|l|l|}
\hline Characteristics & $\begin{array}{l}\text { Frequency } \\
\mathbf{n}(\%)\end{array}$ \\
\hline Gender & \\
\hline Male & $20(64.5)$ \\
Female & $11(35.5)$ \\
\hline Age at diagnosis & \\
\hline$<1$ & $2(6.4)$ \\
$1-4$ & $6(19.3)$ \\
$5-9$ & $14(45.2)$ \\
$10-15$ & $9(29.1)$ \\
\hline Origin & \\
\hline Urban & $18(58.1)$ \\
Rural & $13(41.9)$ \\
\hline Socioeconomic level & \\
\hline Low & $17(54.8)$ \\
Medium & $5(16.1)$ \\
High & $9(29.1)$ \\
\hline Health insurance & \\
\hline Yes & $9(29.1)$ \\
No & $22(70.9)$ \\
\hline Distance between the patient's origin and & \\
center of treatment (Km): & $10(32.3)$ \\
\hline$\leq 20$ & \\
\hline $21-100$ & \\
$101-300$ & $(48.4)$ \\
\hline$>300$ & \\
\hline
\end{tabular}

growth of masses resulting in facial disfigurement and development of pain. Median duration of symptoms before referral to our unit was three months (range: 20 days - 9 months). Bony sites (96.7\%) were more involved than soft tissues sites (3.3\%). Bony sites included the maxillary sinus, ethmoid sinus, body of the mandible, maxillary alveolar process, hard palate, temporomandibular joint, and pterygopalatine fossa. The only case with soft tissue involvement was in the parotid area.

Twenty-four (77.4\%) of the 31 patients presented with primary tumors greater than $5 \mathrm{~cm}$ in diameter and more than $80 \%$ had a parameningeal involvement. According to the Pretreatment Staging System, ${ }^{9} 19.3 \%$ of the patients were stage $2,58.1 \%$ were stage 3 , and $22.6 \%$ were stage 4 ( - Table 4 ).

Regardless of the tumor localization and stage, multidrug chemotherapy regimens were used in all our patients as first line of therapy. Patients with tumors in stage III were treated by chemotherapy in $45.8 \%$ of cases or by chemotherapy + radiotherapy in $45.8 \%$, less than $9 \%$ received chemotherapy + surgery \pm radiotherapy. Patients with stage 4 were treated with chemotherapy exclusively (85.7\%), while only $14.3 \%$ underwent chemotherapy and surgery (- Table 5).

The mean follow-up of all the patients was $11 \pm 12.7$ months, ranging from 7 days to 5 years. During the first year, deaths occurred in $35.5 \%$ of the cases, abandonment of treatment was found in $16.1 \%$. Patients with stage 4 showed a

Table 4 Tumor characteristics

\begin{tabular}{|c|c|}
\hline Characteristics & n (\%) \\
\hline \multicolumn{2}{|c|}{ Duration of Symptoms (months) } \\
\hline $\begin{array}{r}\leq 1 \\
1-3 \\
>3\end{array}$ & $\begin{array}{l}1(3.2) \\
16(51.6) \\
14(45.2)\end{array}$ \\
\hline \multicolumn{2}{|l|}{ Tumor location } \\
\hline $\begin{array}{l}\text { Bony sites } \\
\text { Soft tissues sites }\end{array}$ & $\begin{array}{l}30(96.7) \\
1(3.3)\end{array}$ \\
\hline \multicolumn{2}{|l|}{ Tumor size $(\mathrm{cm})$} \\
\hline $\begin{array}{l}>5 \\
\leq 5\end{array}$ & $\begin{array}{l}24(77.4) \\
7(22.6)\end{array}$ \\
\hline \multicolumn{2}{|c|}{ Parameningeal involvement } \\
\hline $\begin{array}{l}\text { Yes } \\
\text { No }\end{array}$ & $\begin{array}{l}25(80.6) \\
6(19.4)\end{array}$ \\
\hline \multicolumn{2}{|l|}{ IRS grouping } \\
\hline $\begin{array}{l}\text { III } \\
\text { IV }\end{array}$ & $\begin{array}{l}24(77.4) \\
7(22.6)\end{array}$ \\
\hline \multicolumn{2}{|l|}{ Stage } \\
\hline $\begin{array}{l}2 \\
3 \\
4\end{array}$ & $\begin{array}{l}6(19.3) \\
18(58.1) \\
7(22.6)\end{array}$ \\
\hline \multicolumn{2}{|l|}{ Histology } \\
\hline $\begin{array}{l}\text { Embryonal } \\
\text { Alveolar }\end{array}$ & $\begin{array}{l}29(93.5) \\
2(6.5)\end{array}$ \\
\hline \multicolumn{2}{|l|}{ Distant metastases } \\
\hline $\begin{array}{l}\text { Yes } \\
\text { No }\end{array}$ & $\begin{array}{l}7(22.6) \\
24(77.4)\end{array}$ \\
\hline
\end{tabular}


Table 5 Distribution of patients with orofacial RMS by type of treatment and stage at diagnosis

\begin{tabular}{|l|l|l|l|}
\hline \multirow{2}{*}{ Treatment } & \multicolumn{3}{|l|}{ Stage at diagnosis } \\
\cline { 2 - 4 } & $\mathbf{2}$ & $\mathbf{3}$ & $\mathbf{4}$ \\
\hline Chemotherapy & $4(66.7 \%)$ & $7(38.8 \%)$ & $6(85.7 \%)$ \\
\hline Chemotherapy + Radiotherapy & $2(33.3 \%)$ & $9(50.0 \%)$ & - \\
\hline Chemotherapy + Surgery & - & $1(5.6 \%)$ & $1(14.3 \%)$ \\
\hline Chemotherapy + Radiotherapy + Surgery & - & $1(5.6 \%)$ & - \\
\hline Total & $6(100 \%)$ & $18(100 \%)$ & $7(100 \%)$ \\
\hline
\end{tabular}

dismal outcome, with death occurring in $85.7 \%$ and abandonment of treatment in $14.3 \%$. Median survival for these patients was less than 5 months. The 2-year event-free survival rate (EFS) was $17.7 \pm 7.8 \%$ for all the patients (-Fig. 1). According to stage, EFS was $41.7 \pm 22.2 \%$ for stage $2,21.6 \pm 10.9 \%$ for stage 3 , and $0 \%$ for stage $4(p=0.05)$ (-Fig. 2).

\section{Discussion}

Despite the predilection of RMS for the head and neck region, orofacial presentations are rare. ${ }^{4}$ In our population, oral and maxillofacial lesions accounted for $17.2 \%$ of all cases of RMS. The mean age of 8 years derived from this study is younger than the mean age of 10 from Al-Khateeb et $\mathrm{al}^{5}$, but is older than the mean age of 4 years reported by Sbeity et al. ${ }^{10}$ Males were more affected than females, with a male to female ratio of 1.8:1. Embryonal subtype was largely predominant in our cases (93.5\%), supporting previous observations in the oral and perioral region. $5,11,12$

Currently, the majority of our patients present with advanced disease. More than half (58.1\%) of the cases presented in stage 3 , while $19.3 \%$ had stage 2 , and $22.6 \%$

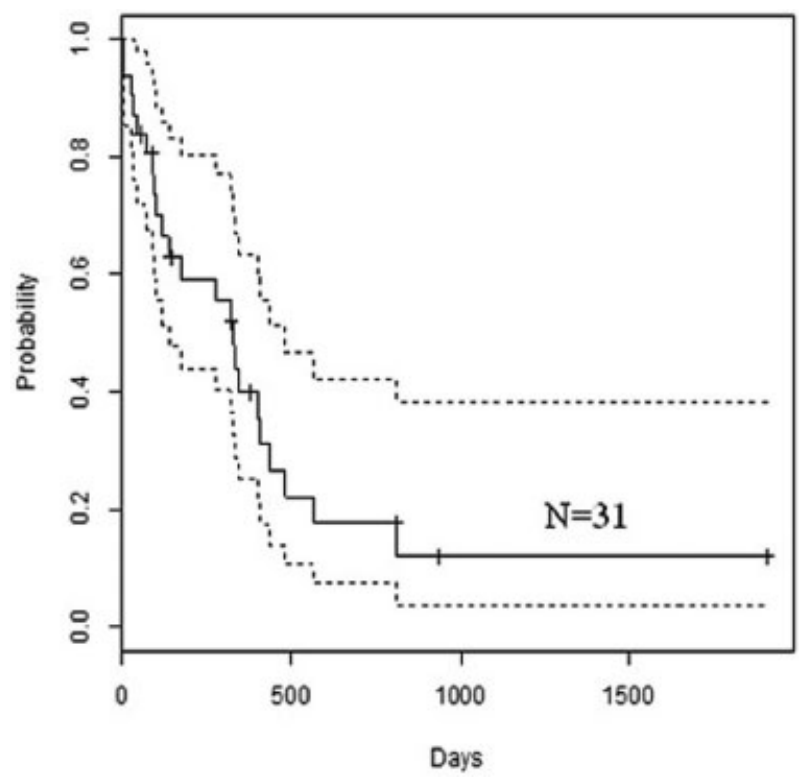

Fig. 1 Event-free survival for patients with orofacial rhabdomyosarcoma. had stage 4 . Tumors more frequently affected the parameningeal sites (80.6\%) and had over $5 \mathrm{~cm}$ in size for $77.4 \%$ of the cases. Furthermore, our patients showed a low survival rate with an EFS of $17.7 \pm 7.8 \%$ for all the patients after two years.

The advanced nature of these diseases in our patients relates to late presentation. We found significant delays in diagnosis and delays in admission to our center of treatment. Time interval from onset of symptoms to referral to hospital ranged from 20 days to 9 months. This time appears excessive in comparison to previous studies where duration of lesions varied between 2 weeks and 4 months. ${ }^{10,12}$ In all delay studies conducted so far, socioeconomic and environmental factors seem to affect access to specialist services and impact the time taken to complete diagnostic investigations. Among our patients, $70.9 \%$ of them have access to a Medical Assistance Scheme (RAMED), which covers costs of care in health centers, dispensaries, diagnostic centers, and public hospitals, but does not shoulder the cost of primary diagnosis examinations (i.e., laboratory exams, radiological explorations, molecular biology), which are typically only available in



Fig. 2 Event-free survival for patients with orofacial rhabdomyosarcoma by stage at presentation. 
private clinics. Populations living far from our hospital face even more obstacles, since traveling to the center of treatment represents a financial cost, in addition to the physical difficulties.

Missed follow-up is another important cause for the dismal prognosis of patients with malignancies in our country. The percentage of patients abandoning treatment in our series was $19.4 \%$. Reasons for abandonment are complex, but often include parental perception of the disease, socio-economic constraints of the families, and access to facilities with appropriate health services. Problems related to transportation and distances and the amount of time required to travel to the treatment center could be other reasons to miss hospital appointments. Regarding our patients, (54.8\%) had lower income, (41.9\%) are localized in rural areas, and $80.6 \%$ are living more than $100 \mathrm{~km}$ from our center of treatment.

On the other hand, lack of uniformity in the treatment protocols was another cause of dismal outcome in our advanced cases. ${ }^{13}$ Unavailability of some chemotherapy drugs (e.g., ifosphamide), lack of locoregional control when needed, and abandonment of treatment were determinant in treatment failure and relapse. Low income and geographic residency were contributory. Based on these findings, at least three critical lines of actions are needed to improve the prognosis of RMS in Morocco: accessibility to health services for indigent patients with complex needs; reduction of delays between the onset of the first symptoms and the beginning of anticancer treatment, availability of cancer drugs, and use of modern treatment even in resource-limited settings.

\section{Conclusion}

This study showed that children with maxillofacial RMS in our institution present late and advanced diseases with a dismal outcome. To enhance the likelihood of disease control, more studies are needed to analyze in detail the distribution delays among patients, practitioners, and the health care system regarding the social and the economic specificities in our population. Improvement of health facilities and use of a multidisciplinary approach are also required.

\section{References}

1 Weber RS, Benjamin RS, Peters LJ, Ro JY, Achon O, Goepfert H. Soft tissue sarcomas of the head and neck in adolescents and adults. Am J Surg 1986;152(4):386-392

2 Chigurupati R, Alfatooni A, Myall RW, Hawkins D, Oda D. Orofacial rhabdomyosarcoma in neonates and young children: a review of literature and management of four cases. Oral Oncol 2002;38(5): 508-515

3 Pappo AS, Shapiro DN, Crist WM, Maurer HM. Biology and therapy of pediatric rhabdomyosarcoma. J Clin Oncol 1995;13(8): 2123-2139

4 Wiener ES. Head and neck rhabdomyosarcoma. Semin Pediatr Surg 1994;3(3):203-206

5 Al-Khateeb T, Bataineh AB. Rhabdomyosarcoma of the oral and maxillofacial region in Jordanians: a retrospective analysis. Oral Surg Oral Med Oral Pathol Oral Radiol Endod 2002;93(5): 580-585

6 Fletcher CDM, Unni KK, Mertens F. World Health Organization Classification of Tumours. Pathology and Genetics of Tumours of Soft Tissue and Bone. Lyon, France: IARC Press; 2002:142-154

7 Antillon F, Castellanos M, Valverde P, et al. Treating Pediatric soft tissue sarcomas in a country with limited resources: the experience of the Unidad Nacional de Oncologia Pediatrica in Guatemala. Pediatr Blood Cancer 2008;51(6):760-764

8 Maurer HM, Beltangady M, Gehan EA, et al. The Intergroup Rhabdomyosarcoma Study-I. A final report. Cancer 1988;61(2):209-220

9 Lawrence W Jr, Anderson JR, Gehan EA, Maurer H. Children's Cancer Study Group. Pediatric Oncology Group. Pretreatment TNM staging of childhood rhabdomyosarcoma: a report of the Intergroup Rhabdomyosarcoma Study Group. Cancer 1997;80(6): $1165-1170$

10 Sbeity S, Abella A, Arcand P, Quintal MC, Saliba I. Temporal bone rhabdomyosarcoma in children. Int J Pediatr Otorhinolaryngol 2007;71(5):807-814

11 Peters E, Cohen M, Altini M, Murray J. Rhabdomyosarcoma of the oral and paraoral region. Cancer 1989;63(5):963-966

12 Fatusi OA, Ajike SO, Olateju SO, Adebayo AT, Gbolahan OO, Ogunmuyiwa SA. Clinico-epidemiological analysis of orofacial rhabdomyosarcoma in a Nigerian population. Int J Oral Maxillofac Surg 2009;38(3):256-260

13 Ndom P. Challenges of anticancer chemotherapy in Africa. Can J Urol 2008;15(1):3909-3911 